\title{
Modelling Surface Roughness in the Function of Torque When Drilling
}

\author{
Zdravko Krivokapić $^{1, *}$, Radoslav Vučurević ${ }^{2}$, Davorin Kramar ${ }^{3}$ (D) and Jelena Šaković Jovanović $^{1}$ \\ 1 Faculty of Mechanical Engineering, University of Montenegro, Podgorica 81000, Montenegro; \\ jelenajov@ucg.ac.me \\ 2 Faculty of Production and Management Trebinje, University of East Sarajevo, \\ Trebinje 89101, Bosnia and Herzegovina; radoslav.vucurevic@fpm.ues.rs.ba \\ 3 Faculty of Mechanical Engineering, University of Ljubljana, Ljubljana 1000, Slovenia; \\ davorin.kramar@fs.uni-lj.si \\ * Correspondence: zdravkok@ucg.ac.me; Tel.: +382-20-242-907
}

Received: 27 January 2020; Accepted: 26 February 2020; Published: 3 March 2020

check for updates

\begin{abstract}
Given the application of a multiple regression and artificial neural networks (ANNs), this paper describes development of models for predicting surface roughness, linking an arithmetic mean deviation of a surface roughness to a torque as an input variable, in the process of drilling enhancement steel EN 42CrMo4, thermally treated to the hardness level of $28 \mathrm{HRC}$, using cruciform blade twist drills made of high speed steel with hardness level of 64-68 HRC. The model was developed using process parameters (nominal diameters of twist drills, speed, feed, and angle of installation of work pieces) as input variables varied at three levels by Taguchi design of experiment and measured experimental data for a torque and arithmetic mean deviation of a surface roughness for different values of flank wear of twist drills. The comparative analysis of the models results and the experimental data, acquired for the inputs at the moment when a wear span reaches a limit value corresponding to a moment of the drills blunting, demonstrates that the neural network model gives better results than the results obtained in the application of multiple linear and nonlinear regression models.
\end{abstract}

Keywords: drilling; torque; roughness; models

\section{Introduction}

A surface roughness appearing as a result of cutting processes has a big impact on functional properties of their products, as well as the quality of products in use. Therefore, determining a co-dependency between the set input and/or measurable process parameters occurring during machining and parameters of surface roughness contributes to the managing of the process in terms of a timely prediction of the process from the aspect of a satisfactory product quality.

A large number of experimental research projects have tried to establish a co-dependency between surface roughness and input parameters for machining processes. The model for predicting the surface roughness, using an arithmetic mean surface roughness deviation $\left(R_{a}\right)$, was developed by applying a multiple regression model and the models based on artificial neural networks (ANNs).

Rodrigues et al. [1] used a regression analysis for developing a model linking a speed $n$ (rev/min), feed $f(\mathrm{~mm} / \mathrm{rev})$, and a depth of a cut $a(\mathrm{~mm})$ with the surface roughness using an arithmetic mean deviation $R_{a}(\mu \mathrm{m})$, by conducting a full plan of the experiment, as well as by varying referred parameters at three levels, when turning a construction steel using tools made of high speed steel (HSS). The corrected determination coefficient in this case was $66.1 \%$, indicating a strong correlation between the surface roughness and referred parameters. 
By applying the Taguchi design of experiment, Çiçek et al. [2] created an optimal combination of machining parameters from the aspect of the surface roughness, when drilling austenitic stainless steel AISI 316 with twist drills made of high speed steel (HSS), subjected to conventional and cryogenic treatments, by varying feed $f(\mathrm{~mm} / \mathrm{rev})$ and cutting speed $v_{\mathcal{c}}(\mathrm{m} / \mathrm{min})$ at two levels. Apart from establishing an optimal combination, by means of a multiple regression analysis, they developed a regression model linking the referred parameters with the surface roughness through an arithmetic mean deviation $R_{a}(\mu \mathrm{m})$, with the determination coefficient of $96.3 \%$.

Based on the application of Taguchi design in an experiment when drilling OHNS material, tool steel broadly used in tool manufacturing, with high speed steel (HSS) twist drills, and a regression analysis, using commercially available software MINITAB 13, Kumar and Packiaraj [3] developed models linking an arithmetic mean deviation of a surface roughness $R_{a}(\mu \mathrm{m})$ and a deviation of a hole diameter from a nominal value $\Delta D(\mathrm{~mm})$ to a cutting speed $v_{\mathcal{C}}(\mathrm{m} / \mathrm{min})$, feed $f(\mathrm{~mm} / \mathrm{rev})$, and a twist drill diameter $d(\mathrm{~mm})$. The developed models yielded good results, and the analysis of variances showed that feed and cutting speed have key impacts on a surface roughness and the deviation of a hole diameter from its nominal value, which is necessary to create such a combination of these parameters that should reduce variations affecting the quality of a hole made in OHNS material.

With the application of Taguchi design in an experiment, analysis of variance, and a regression analysis, Ficici et al. [4] researched the impact of tool modifications (twist drill cutting edge grinding in $\mu \mathrm{m})$, cutting speed $v_{\mathcal{C}}(\mathrm{m} / \mathrm{min})$, and feed $f(\mathrm{~mm} / \mathrm{rev})$ on the roughness of a hole when drilling austenitic stainless steel AISI 304 with twist drills made of high speed steel (HSS). By conducting the experiment and through data analysis, they found an optimal combination of the parameters, while alternative analysis provided them with data showing that the tool modifications, cutting speed $v_{\mathcal{C}}(\mathrm{m} / \mathrm{min})$, and feed $f(\mathrm{~mm} / \mathrm{rev})$ affect a surface roughness in drilling process at the levels of $74.25 \%, 13.72 \%$, and $6.25 \%$, respectively. With the development of the regression model, they connected the above parameters to the surface roughness through an arithmetic mean deviation $R_{a}(\mu \mathrm{m})$, and both by conducting the confirmation experiment and using an optimal combination of parameters, they determined that the prediction error is $4.34 \%$.

Based on the results of the experiment conducted by an BBD (Box Behnken Design) experiment, Kumari et al. [5] developed a mathematical model linking the speed $n(\mathrm{rev} / \mathrm{min})$, the velocity of an auxiliary motion $v_{f}(\mathrm{~mm} / \mathrm{min})$, and the concentration of cooling agents $(\%)$ to an arithmetic mean deviation of surface roughness $R_{a}(\mu \mathrm{m})$, when drilling stainless steel SS 304 with twist drills made of high speed steel (HSS), while Xiao et al. [6], by applying Taguchi design of experiment and with an acceptable prediction error, developed a regression model for predicting surface roughness in case of stainless steel turning.

Based on applying a genetic programming, Brezocnik et al. [7] developed models for predicting surface roughness that produced good results in the comparison with the experimental ones, using a speed, feed, depth of cut, and vibrations between the tools and the work piece as independent variables, with the surface roughness as a dependable variable expressed in an arithmetic mean deviation, while, by applying a regression analysis, Sekulic et al. [8] developed a model for predicting surface roughness when milling steel X210CR12 hardness 58 HRC, which was used as a basis for the model development with the application of a genetic algorithm (GA) and a newly developed grey wolf optimizer algorithm (GWO) with a prediction accuracy calculated at $91.8 \%$.

Akkuş and Asilturk [9] developed a model for predicting a surface roughness based on ANNs when turning tempered steel AISI 4140. Testing of the subject model gave favourable results with a mean square deviations of 0.0497795 . Given the comparison of the results of the referred model with the data of the fuzzy model and a mathematical model, developed through the same research, it can be concluded that artificial intelligence can be successfully used for the prediction purposes.

By conducting Taguchi design of experiment and by using inputs for a cutting speed $v_{c}(\mathrm{~m} / \mathrm{min})$, speed $n(\mathrm{rev} / \mathrm{min})$ and the depth of a cut $a(\mathrm{~mm})$, varied at three levels, when turning AA 6351 alloy, Konanki and Sadineni [10] developed a model for predicting a surface roughness based on ANNs, 
via an arithmetic mean deviation $R_{a}(\mu \mathrm{m})$, with an average testing error of $2.24 \%$. The predicted model's values were very close to the experimental values confirming that acceptable prediction model was developed.

Rashid and Lani [11] used a multiple regression and ANNs for developing the model of a surface roughness when milling aluminium. By conducting the experiment, using full factorial plan and setting multiple regression coefficients, they developed a model connecting a surface roughness expressed in an arithmetic mean deviation of the profile roughness $R_{a}(\mu \mathrm{m})$, speed $n(\mathrm{rev} / \mathrm{min})$, velocity of the auxiliary motion $v_{f}(\mathrm{~mm} / \mathrm{min})$ and the depth of a cut $a(\mathrm{~mm})$ with a prediction accuracy of $86.7 \%$. The prediction by means of ANNs gave the best results, with a mean error of $6.42 \%$, which proved that the ANN predicted a surface roughness with a $93.58 \%$ accuracy.

Given the case of turning a composite material with an aluminium metal matrix, based on both, the results of experiments obtained by CCD (Central Composite Design) and by applying regression analysis and ANN with multiple outputs, Tamang and Chandrasekaran [12] developed models connecting a cutting speed $v_{\mathcal{c}}(\mathrm{m} / \mathrm{min})$, velocity of the auxiliary motion $v_{f}(\mathrm{~mm} / \mathrm{min})$ and the depth of cut $a(\mathrm{~mm})$ with both an arithmetic mean deviation of a surface roughness $R_{a}(\mu \mathrm{m})$ and a machining tool wear $V B(\mathrm{~mm})$. By comparing their prediction results of developed models, they got data showing that ANNs yield a higher prediction accuracy of about $92 \%$ for a tool wear prediction and around $95 \%$ for the predicting a surface roughness.

Given the application of a regression analysis and ANNs on the results obtained by conducting a full design of the experiment when turning red brass, Hanief and Wani [13] developed models linking the cutting speed $v_{c}(\mathrm{~m} / \mathrm{min})$, feed $f(\mathrm{~mm} / \mathrm{rev})$ and the depth of a cut $a(\mathrm{~mm})$ to the arithmetic mean deviation of a surface roughness $R_{a}(\mu \mathrm{m})$. Maximal prediction errors for the obtained models were $9.9 \%$ and $9.5 \%$, respectively, an advantage was therefore given to the model obtained through the application of ANNs.

The referred models yield good approximations of experimental results, but they do not consider an impact character of the size of a tool wear on the surface roughness.

Based on the experimental research of turning and drilling of soft annealed pearlite-ferrite steel, Nedić et al. [14] established the presence of a polynomial dependency in the form of the third degree polynomial, between an arithmetic mean deviation of a surface roughness $R_{a}(\mu \mathrm{m})$ and a machining tool wear $V B(\mathrm{~mm})$.

Krivokapić et al. [15] drew a conclusion that the development of a model for an indirect monitoring of a tool wear during steel machining, and the establishment of a correlation between the surface roughness and the provider of information about the tool wear phenomena (axial force and torque), allows surface roughness prediction based on a tool wear data.

Mathew et al. [16] showed that a tool wear span $V B(\mathrm{~mm})$, when milling EN-8 medium carbon steel, can be connected with the level of an acoustic emission expressed through a mean stress value $A E$ $(\mathrm{mV})$, while Lin et al. [17] showed that it is possible to use ANNs for the surface roughness prediction based on a vibration signal when milling medium carbon steel S45C.

Bhaskaran et al. [18] researched the impact of a tool wear when milling high-alloy steel AISI-D3, with hardness of $60 \mathrm{HRC}$, on the signal of an acoustic emission and a surface roughness of the work piece and showed that exceedances of certain limits leads to sudden increases in certain parameters of acoustic emissions, as well as in the value of a surface roughness.

Spaić and Marinović [19], by applying ANNs, established a model for an axial drilling force $F_{3}$ $(\mathrm{N})$ depending on the width of a wear band $V B(\mathrm{~mm})$, based on experimental results obtained when drilling high strength and hardness steel EN 42CrMo4 with twist drills made of high speed steel. The paper showed that ANNs can be used for predicting axial cutting force as a provider of information on cutting tools' wear.

Xu et al. [20] showed that a tool wear $V B(\mathrm{~mm})$, when drilling aluminium alloys, can be predicted by ANNs using process input parameters, such as a cut depth $a(\mathrm{~mm})$, speed $n$ (rev/min), and a feed $f$ 
$(\mathrm{mm} / \mathrm{rev})$, complemented by the values of measurable process parameters, such as an axial cutting force $F_{3}(\mathrm{~N})$ and torque $M(\mathrm{Nm})$.

Given the application of a regression analysis and ANNs, when drilling steel for enhancement EN 42CrMo4 hardness 17 HRC, Vučurević et al. [21] developed models for the prediction of the surface roughness, using a twist drill diameter $d(\mathrm{~mm})$, speed $n(\mathrm{rev} / \mathrm{min})$, feed $f(\mathrm{~mm} / \mathrm{rev})$, installation angle of the work piece $\varepsilon\left({ }^{\circ}\right)$ and an axial drill force $F_{3}(\mathrm{~N})$ as input parameters. Regarding the development of the model establishing a connection between the machining parameters and an axial drilling force, which is in correlation with a machining tool wear, with the surface roughness expressed in arithmetic mean deviation $R_{a}(\mu \mathrm{m})$, they came to a conclusion that it is possible to develop models for the surface roughness prediction based on an axial drilling force that is in correlation with a tool's wear. Based on a comparative analysis of the results obtained from the model, they found out that application of ANNs provides better prediction results.

Taking into consideration the aforementioned, an opportunity to develop a model of a multiple regression and ANN model, to include process input parameters (nominal twist drill diameter, speed, feed, and angle of installation of the work piece) and a torque as a measurable parameter of the machining related to machining tool wear, has appeared.

The goal of this paper, based on the experimental results obtained by using the Taguchi design of experiment, is to obtain a model which, for given values of input parameters (nominal twist drill diameter, speed, feed, angle of installation of the work piece) and measurable parameter (torque), will be able to predict the surface roughness.

This paper achieves the inclusion of tool wear in the models of surface roughness prediction through torque, as a measurable parameter during the machining process, which is correlated with tool wear, which was not the case in previous studies. The basic novelty of the paper is the ability to monitor and predict the process from the aspect of mean arithmetic deviation of surface roughness without stopping the process and measuring it, using an adequate model that includes torque as a measurable parameter.

\section{Materials and Methods}

This research used Taguchi orthogonal matrix L $\mathrm{L}_{9}[22,23]$ with nine combinations of machining process parameters, which predicts varying of four experiment factors on three levels, as a basis for conducting experimental research, required for an obtaining data for the purpose of developing the model.

The varying factors of the experiment, nominal twist drill diameter $(d)$, speed $(n)$, feed $(f)$, and an angle of the installation of the work piece $(\varepsilon)$ as an additional factor, were determined based on the twist drills manufacturer's recommendations. The adopted values of the experiment factor are shown in Table 1.

Table 1. The experiment's factor value.

\begin{tabular}{ccccc}
\hline No. & $\boldsymbol{d}(\mathbf{m m})$ & $\boldsymbol{n}(\mathbf{r e v} / \mathbf{m i n})$ & $f(\mathbf{m m} / \mathbf{r e v})$ & $\varepsilon\left(\mathbf{(}^{\mathbf{0}}\right)$ \\
\hline 1. & 3 & 300 & 0.03 & 0 \\
2. & 5 & 500 & 0.05 & 3 \\
3. & 8 & 800 & 0.10 & 5 \\
\hline
\end{tabular}

Using the orthogonal matrix $\mathrm{L}_{9}$ and the adopted values of the experiment factors, design of the experiment, given in Table 2, is formed.

The experiment was planned to be conducted using twist drills (TD) DIN 338 made of high-speed steel EN HS6-5-2 by means of a grinding technology, hardness 64-68 HRC, in black version with a cruciform blade (CB), manufactured by "Swisslion Industrija Alata, a.d. Trebinje". The chemical composition of EN HS6-5-2 steel is shown in Table 3. 
Table 2. Design of experiment.

\begin{tabular}{ccccc}
\hline \multirow{2}{*}{$\begin{array}{c}\text { No. of } \\
\text { Combination }\end{array}$} & $\boldsymbol{4}$ Factors \\
\cline { 2 - 5 } & $\boldsymbol{d}(\mathbf{m m})$ & $\boldsymbol{n}$ (rev/min) & $f(\mathbf{m m} / \mathbf{r e v})$ & $\varepsilon\left[^{\mathbf{o}}\right]$ \\
\hline 1. & 3 & 300 & 0.03 & 0 \\
2. & 3 & 500 & 0.05 & 3 \\
3. & 3 & 800 & 0.10 & 5 \\
4. & 5 & 300 & 0.05 & 0 \\
5. & 5 & 500 & 0.10 & 3 \\
6. & 5 & 800 & 0.03 & 3 \\
7. & 8 & 300 & 0.10 & 5 \\
8. & 8 & 500 & 0.03 & 0 \\
\hline
\end{tabular}

Table 3. The chemical composition of steel EN HS6-5-2 (\%).

\begin{tabular}{ccccccccc}
\hline C & W & Mo & Cr & V & Si & Mn & P & S \\
\hline $0.82-0.9$ & $5.5-6.75$ & $4.5-5.5$ & $3.8-4.4$ & $1.75-2.2$ & $0.2-0.45$ & $0.15-0.4$ & $\leq 0.03$ & $\leq 0.03$ \\
\hline
\end{tabular}

The test tubes made of steel EN 42CrMo4, thermally treated to hardness $28 \mathrm{HRC}$, were provided as the material for conducting the experiment. The chemical composition of steel EN 42CrMo4 is shown in Table 4.

Table 4. The chemical composition of steel EN 42CrMo4 (\%).

\begin{tabular}{ccccccc}
\hline $\mathbf{C}$ & $\mathbf{S i}$ & $\mathbf{M n}$ & $\mathbf{P}$ & $\mathbf{S}$ & $\mathbf{C r}$ & Mo \\
\hline $0.38-0.45$ & $0.15-0.4$ & $0.5-0.8$ & $\leq 0.035$ & $\leq 0.035$ & $0.9-1.2$ & $0.15-0.3$ \\
\hline
\end{tabular}

The test tube dimensions, determined based on a planned drilling depth $l=3 d$, are shown in Table 5.

Table 5. The test tube dimensions.

\begin{tabular}{cccc}
\hline Twist Drills & $\boldsymbol{l}(\mathbf{m m})$ & Test Tube Diameter $(\mathbf{m m})$ & Test Tube Thickness $(\mathbf{m m})$ \\
\hline DIN 338 Ø3.00 & 9 & 60 & 15 \\
DIN 338 Ø5.00 & 15 & 60 & 20 \\
DIN 338 Ø 8.00 & 24 & 60 & 30 \\
\hline
\end{tabular}

The experiment was conducted using a CNC milling machine MILL 250 (EMCO MAIER Ges.m.b.H., Salzburger, Austria) with the option of achieving a maximal spindle speed of $10000 \mathrm{rev} / \mathrm{min}$, velocity of auxiliary motion range of $0-10 \mathrm{~m} / \mathrm{min}$, the option of achieving maximal torque of $41 \mathrm{Nm}$, and EMCO WinNC numerical control using software SIEMENS Sinumerik 810/840D.

The size of a twist drill flank wear was measured with an optical device for measuring geometrical elements of twist drills PG 100 (GÜHRING oHG, Albstadt, Germany), with the option of digital readout of measured values below $10 \mu \mathrm{m}$ with precision $\pm 2.5 \%$, while the recording of the torque values during the process was performed using a measuring chain for measuring axial force and torque (KISTLER GROUP, Winterthur, Switzerland) having a measuring range of up to $100 \mathrm{Nm}$ for the torque with precision $\pm 1.2 \%$. The measurement of an arithmetic mean deviation value of the machined surface roughness profile was conducted using a SURTRONIC 25 surface roughness tester (TAYLOR HOBSON Ltd., Leicester, UK) with a measurement range of up to $300 \mu \mathrm{m}$ with precision $\pm 2 \%$.

Torque $(M)$ was measured during the entire drilling process, and the mean torque was taken as relevant. An overview of the torque measuring equipment used is given in Figure 1. 


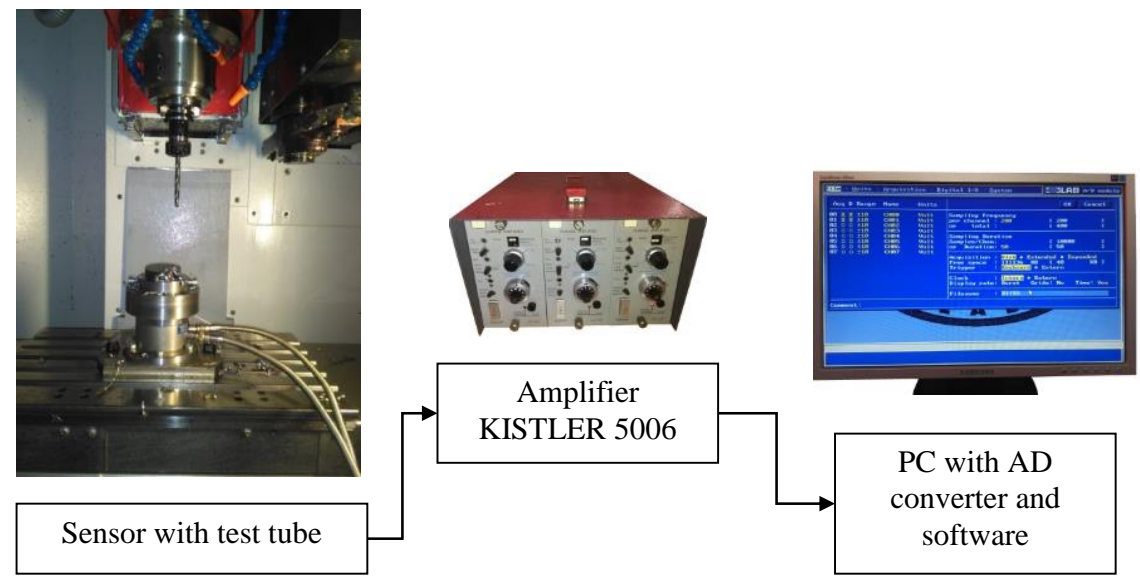

Figure 1. Torque measuring equipment.

The surface roughness was measured by measuring the roughness parameters according to ISO 4287 by rotating the test tube by a $90^{\circ}$ and measuring it at four characteristic points, where by the mean value of the measured values was assumed to be decisive if the measurement uncertainty was satisfactory. The following information was used for the measurement: Gaussian filter, cut-off $0.800 \mathrm{~mm}$, and evaluation length $4.00 \mathrm{~mm}$. Before starting the measurement, the measuring instrument was validated with a reference standard with a mean arithmetic deviation of surface roughness $R_{a}=6.00 \mu \mathrm{m}$.

\section{Results}

According to previous research [9-11], the experiment was conducted in order to obtain a model based on a regression analysis, as well as the model based on ANNs. The results of the research indicate the usability of the model based on the regression analysis and the model based on ANNs in the prediction of a surface roughness.

\subsection{The Experimental Results}

In the experiment conducted by drilling holes depth $l=3 d$ with different input parameters of the drilling process (nominal diameter, speed, feed, and angle of installation of the work piece), the values of torque $M(\mathrm{Nm})$ and arithmetic mean deviation of the surface roughness profile $R_{a}(\mu \mathrm{m})$ were acquired at the beginning of the process, at the moment of medium wear, and at the moment of tool blunting. Table 6 shows acquired values.

Table 6. The experimental results.

\begin{tabular}{|c|c|c|c|c|c|c|c|c|c|c|}
\hline \multirow[b]{2}{*}{ No. } & \multirow[b]{2}{*}{$d(\mathrm{~mm})$} & \multirow{2}{*}{$\begin{array}{c}n \\
(\mathrm{rev} / \mathrm{min})\end{array}$} & \multirow{2}{*}{$\begin{array}{c}f \\
(\mathrm{~mm} / \mathrm{rev})\end{array}$} & \multirow[b]{2}{*}{$\varepsilon\left[^{0}\right]$} & \multicolumn{2}{|c|}{$V B=0 \mathrm{~mm}$} & \multicolumn{2}{|c|}{$V B=0.02 d$} & \multicolumn{2}{|c|}{$V B=0.04 d$} \\
\hline & & & & & $\begin{array}{c}M \\
(\mathrm{Nm})\end{array}$ & $\begin{array}{c}R_{a} \\
(\mu \mathrm{m})\end{array}$ & $\begin{array}{c}M \\
(\mathrm{Nm})\end{array}$ & $\begin{array}{c}R_{a} \\
(\mu \mathrm{m})\end{array}$ & $\begin{array}{c}M \\
(\mathrm{Nm})\end{array}$ & $\begin{array}{c}R_{a} \\
(\mu \mathrm{m})\end{array}$ \\
\hline 1. & 3 & 300 & 0.03 & 0 & 0.3 & 0.32 & 0.43 & 0.35 & 0.58 & 0.57 \\
\hline 2. & 3 & 500 & 0.05 & 3 & 0.23 & 0.7 & 0.28 & 0.83 & 0.33 & 0.97 \\
\hline 3. & 3 & 800 & 0.10 & 5 & 0.49 & 2.95 & 0.58 & 3.31 & 0.66 & 4.01 \\
\hline 4. & 5 & 300 & 0.05 & 5 & 0.75 & 0.71 & 0.88 & 0.89 & 1.12 & 1.31 \\
\hline 5. & 5 & 500 & 0.10 & 0 & 1.3 & 2.79 & 1.46 & 3.22 & 1.63 & 3.49 \\
\hline 6. & 5 & 800 & 0.03 & 3 & 0.45 & 1.62 & 0.46 & 1.99 & 0.5 & 2.65 \\
\hline 7. & 8 & 300 & 0.10 & 3 & 3 & 2.45 & 3.06 & 3.34 & 3.13 & 4.22 \\
\hline 8. & 8 & 500 & 0.03 & 5 & 1.01 & 1.96 & 1.2 & 2.55 & 1.4 & 3.14 \\
\hline 9. & 8 & 800 & 0.05 & 0 & 1.61 & 2.13 & 1.68 & 2.67 & 1.74 & 3.15 \\
\hline
\end{tabular}


A graphical representation of the results of one measurement of surface roughness, at the moment of tool blunting for the first combination of experiment factors, is shown in Figure 2.

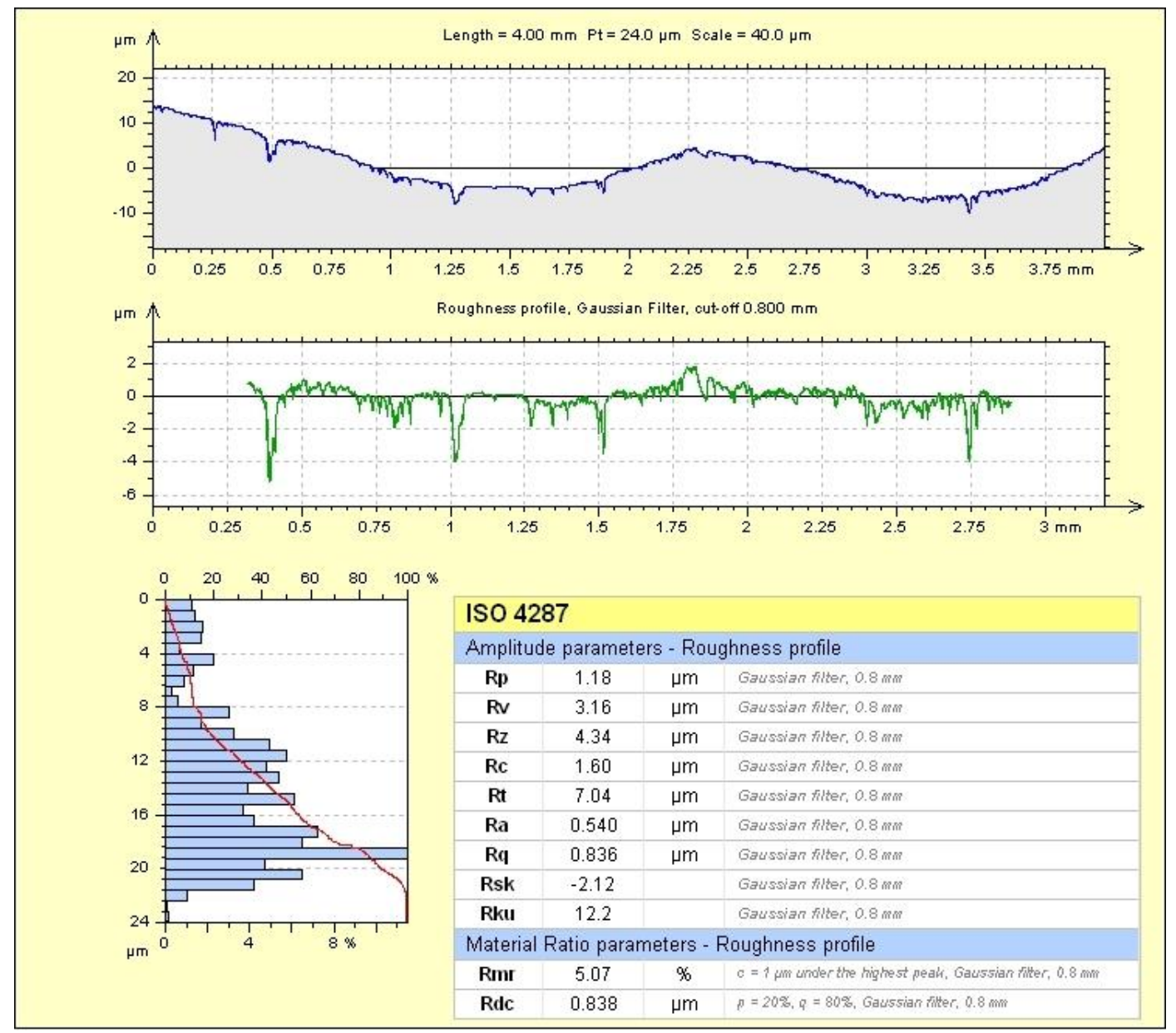

Figure 2. Surface roughness measurement.

The values of the mean arithmetic deviation of surface roughness and torque are rounded to two decimal places, taking into account the corresponding measurement uncertainty. The determined measurement uncertainties $(u)$ and relative measurement uncertainties $\left(u_{r}\right)$ for the values of mean arithmetic deviation of surface roughness $\left(R_{a}\right)$ are given in Table 7 .

Table 7. Measurement uncertainties for $R_{a}$ values.

\begin{tabular}{|c|c|c|c|c|c|c|c|c|c|}
\hline \multirow{2}{*}{ No. } & \multicolumn{3}{|c|}{$V B=0 \mathrm{~mm}$} & \multicolumn{3}{|c|}{$V B=0.02 d$} & \multicolumn{3}{|c|}{$V B=0.04 d$} \\
\hline & $\begin{array}{c}R_{a} \\
(\mu \mathrm{m})\end{array}$ & $u(\mu \mathrm{m})$ & $u_{r}(\%)$ & $\begin{array}{c}R_{a} \\
(\mu \mathrm{m})\end{array}$ & $u(\mu \mathrm{m})$ & $u_{r}(\%)$ & $\begin{array}{c}R_{a} \\
(\mu \mathrm{m})\end{array}$ & $u(\mu \mathrm{m})$ & $u_{r}(\%)$ \\
\hline 1. & 0.32 & 0.01 & 3.13 & 0.35 & 0.003 & 0.86 & 0.57 & 0.01 & 1.75 \\
\hline 2. & 0.7 & 0.012 & 1.71 & 0.83 & 0.003 & 0.36 & 0.97 & 0.02 & 2.06 \\
\hline 3. & 2.95 & 0.08 & 2.71 & 3.31 & 0.053 & 1.6 & 4.01 & 0.065 & 1.62 \\
\hline 4. & 0.71 & 0.021 & 2.96 & 0.89 & 0.019 & 2.13 & 1.31 & 0.023 & 1.76 \\
\hline 5. & 2.79 & 0.031 & 1.11 & 3.22 & 0.033 & 1.02 & 3.49 & 0.069 & 1.98 \\
\hline 6. & 1.62 & 0.032 & 1.98 & 1.99 & 0.044 & 2.21 & 2.65 & 0.092 & 3.47 \\
\hline 7. & 2.45 & 0.055 & 2.24 & 3.34 & 0.015 & 0.45 & 4.22 & 0.083 & 1.97 \\
\hline 8. & 1.96 & 0.135 & 4.8 & 2.55 & 0.013 & 0.51 & 3.14 & 0.082 & 2.61 \\
\hline 9. & 2.13 & 0.092 & 4.32 & 2.67 & 0.053 & 1.99 & 3.15 & 0.046 & 1.46 \\
\hline
\end{tabular}


The relative measurement uncertainties for the torque values and the size of a twist drill flank wear, rounded to two decimal places, are up to $5 \%$.

\subsection{The Regression Models}

The development of the model of a multiple linear regression in case of presence of a statistical sample size $n$, which could be used to establish a connection between a dependable variable $y$ and non-dependable variables $x_{1}, x_{2}, \ldots, x_{k}$, comes down to an assessment of unknown parameters of the model with the method of the least squares and forming the following model:

$$
\hat{y}=b_{0}+b_{1} x_{1}+b_{2} x_{2}+\ldots+b_{k} x_{k}
$$

Since a dependable variable $R_{a}$ is in function of four input parameters of the process (nominal diameter of the twist drill $-d$, speed $-n$, feed $-f$, and angle of installation of the work piece $-\varepsilon$ ), and the size of a twist drill flank wear that can be connected to the torque- $M$, the multiple linear regression model (MLRM) was created, while using the experimental results for $V B=0.04 d$ and determining the value of parameters $b_{0}, \ldots, b_{5}$ by the method of least squares, in the following way:

$$
\hat{R}_{a}=b_{0}+b_{1} \cdot d+b_{2} \cdot n+b_{3} \cdot f+b_{4} \cdot \varepsilon+b_{5} \cdot M
$$

The model's parameters with a standard regression error $s$, coefficient of determination $R^{2}$, adjusted coefficient of determination $\bar{R}^{2}$, and standard parameter error $s_{b_{j}}(j=1, \ldots, 5)$ are shown in Table 8 .

Table 8. The parameters of a multiple linear regression model with a torque for twist drills (TD) drilling with cruciform blade (CB) in test tubes hardness 28 HRC.

\begin{tabular}{ccccc}
\hline \multirow{2}{*}{ Model Parameter } & Parameter Value & $\boldsymbol{s}_{\boldsymbol{b}_{j}}$ & $\boldsymbol{t}_{j}=\frac{\boldsymbol{b}_{j}}{\boldsymbol{s}_{\boldsymbol{b}_{j}}}$ & \multicolumn{1}{c}{} \\
\hline$b_{0}$ & & - & - & $\mathbf{0 . 6 4 8}$ \\
$b_{1}$ & -2.244 & 0.105 & 2.159 & $R^{2}$ \\
$b_{2}$ & 0.227 & 0.001 & 2.742 & 0.913 \\
$b_{3}$ & 0.003 & 7.333 & 3.269 & $\bar{R}^{2}$ \\
$b_{4}$ & 23.973 & 0.105 & 0.933 & 0.768 \\
$b_{5}$ & 0.098 & 0.261 & 1.276 & \\
\hline
\end{tabular}

Since all the values $\left|t_{j}\right|<t$ for the significance level $p=0.02$, the estimation of a dependable variable $R_{a}$ based on variables $d, n, f, \varepsilon$, and $M$ makes sense.

Taking into account the assumption on the presence of a nonlinear relationship between the surface roughness and machining input parameters, the multiple nonlinear regression model was formed:

$$
\hat{R}_{a}=b_{0} \cdot d^{b_{1}} \cdot n^{b_{2}} \cdot f^{b_{3}} \cdot \varepsilon^{b_{4}} \cdot M^{b_{5}}
$$

In order to determine the model parameters, the nonlinear regression model is reduced by a logarithmic transformation to a linear regression model in the form:

$$
\log \hat{R}_{a}=\log b_{0}+b_{1} \cdot \log d+b_{2} \cdot \log n+b_{3} \cdot \log f+b_{4} \cdot \log \varepsilon+b_{5} \cdot \log M
$$

Table 9 presents the parameters of the transformed model with a standard regression error $s$, coefficient of determination $R^{2}$, adjusted coefficient of determination $\bar{R}^{2}$, and standard parameter error $s_{b_{j}}(j=1, \ldots, 5)$. 
Table 9. The parameters of the transformed regression model with a torque for TD drilling with CB in test tube hardness 28 HRC.

\begin{tabular}{ccccc}
\hline Model Parameter & Parameter Value & $\boldsymbol{s}_{\boldsymbol{b}_{j}}$ & $\boldsymbol{t}_{j}=\frac{\boldsymbol{b}_{j}}{\boldsymbol{s}_{\boldsymbol{b}_{j}}}$ & $\boldsymbol{s}$ \\
\hline $\log b_{0}$ & -2.515 & & - & $\mathbf{0 . 1 1 4}$ \\
$b_{1}$ & -0.433 & 0.218 & -2.038 & $R^{2}$ \\
$b_{2}$ & 1.253 & 0.218 & 5.758 & 0.95 \\
$b_{3}$ & 0.113 & 0.177 & 0.638 & $\bar{R}^{2}$ \\
$b_{4}$ & 0.024 & 0.008 & 2.874 & 0.865 \\
$b_{5}$ & 1.038 & 0.128 & 8.087 & \multicolumn{1}{c}{} \\
\hline
\end{tabular}

Since all the values $\left|t_{j}\right|<t$ for the significance level $p=0.002$, the estimation of a dependable variable $\log R_{a}$ based on variables $\log d, \log n, \log f, \log \varepsilon$, and $\log M$ makes sense.

When forming regression models, the data given in the Table 10 was used.

Table 10. Regression models formation data.

\begin{tabular}{cccccccccccccc}
\hline No. & $\boldsymbol{d}$ & $\boldsymbol{n}$ & $\boldsymbol{f}$ & $\boldsymbol{\varepsilon}$ & $\boldsymbol{M}$ & $\boldsymbol{R}_{\boldsymbol{a}}$ & $\mathbf{N o .}$ & $\log \boldsymbol{l}$ & $\log \boldsymbol{n}$ & $\log f$ & $\log \varepsilon$ & $\log \boldsymbol{M}$ & $\log \boldsymbol{R}_{\boldsymbol{a}}$ \\
\hline 1. & 3 & 300 & 0.03 & 0 & 0.58 & 0.57 & 1. & 0.477 & 2.477 & -1.52 & -9 & 1.761 & -0.245 \\
2. & 3 & 500 & 0.05 & 3 & 0.33 & 0.97 & 2. & 0.477 & 2.699 & -1.3 & 0.477 & 1.514 & -0.015 \\
3. & 3 & 800 & 0.1 & 5 & 0.66 & 4.01 & 3. & 0.477 & 2.903 & -1 & 0.699 & 1.818 & 0.603 \\
4. & 5 & 300 & 0.05 & 5 & 1.12 & 1.31 & 4. & 0.699 & 2.477 & -1.3 & 0.699 & 2.047 & 0.117 \\
5. & 5 & 500 & 0.1 & 0 & 1.63 & 3.49 & 5. & 0.699 & 2.699 & -1 & -9 & 2.212 & 0.543 \\
6. & 5 & 800 & 0.03 & 3 & 0.5 & 2.65 & 6. & 0.699 & 2.903 & -1.52 & 0.477 & 1.699 & 0.423 \\
7. & 8 & 300 & 0.1 & 3 & 3.13 & 4.22 & 7. & 0.903 & 2.477 & -1 & 0.477 & 2.495 & 0.625 \\
8. & 8 & 500 & 0.03 & 5 & 1.4 & 3.14 & 8. & 0.903 & 2.699 & -1.52 & 0.699 & 2.146 & 0.497 \\
9. & 8 & 800 & 0.05 & 0 & 1.74 & 3.15 & 9. & 0.903 & 2.903 & -1.3 & -9 & 2.24 & 0.498 \\
\hline
\end{tabular}

To determine the influence of each input factor on surface roughness, the average signal-to-noise ratio $(\mathrm{S} / \mathrm{N})$ was calculated for each factor and level for the data obtained at the beginning of the process. The calculated values are shown graphically in Figure 3. It can be observed that the smallest influence on the surface roughness, expressed by the mean arithmetic deviation $\left(R_{a}\right)$, the angle of installation of the test tube $(\varepsilon)$, and the largest influence has the feed $(f)$.

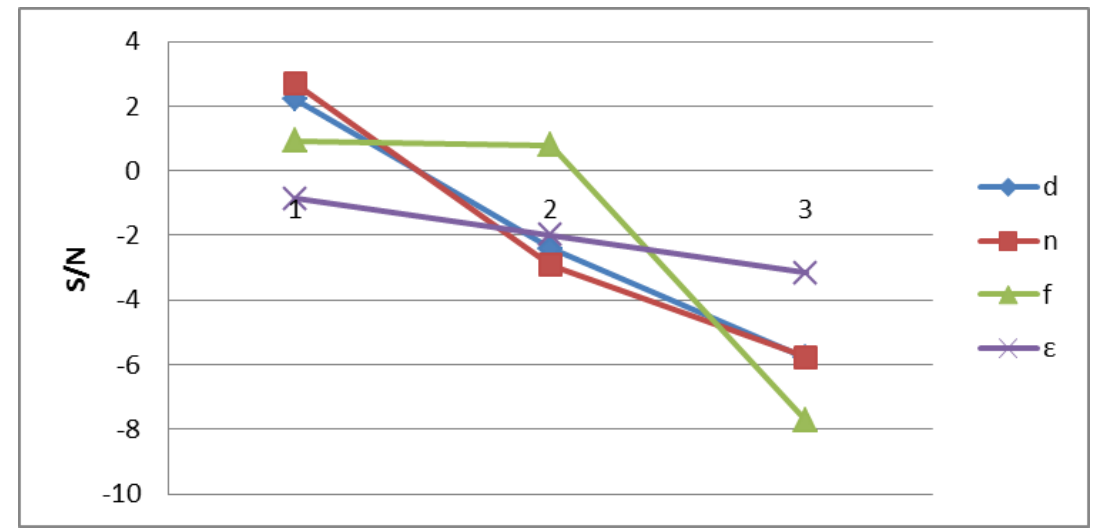

Figure 3. Average signal-to-noise ratio $(\mathrm{S} / \mathrm{N})$ ratio of factors and levels.

\subsection{The Artificial Neural Network Model}

The ANN model (ANNM), with multiple inputs (nominal twist drill diameter, speed, feed, angle of installation of the work piece, and torque) and one output (arithmetic mean deviation of surface roughness) was developed with the application of MATLAB software package using back propagation 
ANN. In order to obtain a model that will give an error of less than $5 \%$ for each individual result in relation to the experimental result, ANN were trained, first with a single hidden layer with a sigmoid transfer function and a linear transfer function in the output layer, and then with two hidden layers. The training was performed with LEARNGDM learning function.

ANNs training was performed with an arithmetic mean deviation of the surface roughness as a target function, input combinations of machining parameters, and the torque, measured for the flank wear value of the twist drills $V B=0 \mathrm{~mm}$ and $V B=0.02 d$ and calculated for the flank wear value of the twist drills $V B=0.01 d$ and $V B=0.03 d$. Training data for ANNs are given in Table 11 .

Table 11. Training data for artificial neural networks (ANNs).

\begin{tabular}{|c|c|c|c|c|c|c|c|c|c|c|c|c|c|}
\hline \multirow{2}{*}{ No. } & \multicolumn{5}{|c|}{ Inputs } & \multirow{2}{*}{$\begin{array}{c}\text { Output } \\
\qquad R_{a}\end{array}$} & \multirow{2}{*}{ No. } & \multicolumn{5}{|c|}{ Inputs } & \multirow{2}{*}{$\begin{array}{c}\text { Output } \\
\qquad R_{a}\end{array}$} \\
\hline & $d$ & $n$ & $f$ & $\varepsilon$ & $M$ & & & $d$ & $n$ & $f$ & $\varepsilon$ & $M$ & \\
\hline 1. & 3 & 300 & 0.03 & 0 & 0.3 & 0.32 & 19. & 3 & 300 & 0.03 & 0 & 0.43 & 0.35 \\
\hline 2. & 3 & 500 & 0.05 & 3 & 0.23 & 0.7 & 20. & 3 & 500 & 0.05 & 3 & 0.28 & 0.83 \\
\hline 3. & 3 & 800 & 0.1 & 5 & 0.49 & 2.95 & 21. & 3 & 800 & 0.1 & 5 & 0.58 & 3.31 \\
\hline 4. & 5 & 300 & 0.05 & 5 & 0.75 & 0.71 & 22. & 5 & 300 & 0.05 & 5 & 0.88 & 0.89 \\
\hline 5. & 5 & 500 & 0.1 & 0 & 1.3 & 2.79 & 23. & 5 & 500 & 0.1 & 0 & 1.46 & 3.22 \\
\hline 6. & 5 & 800 & 0.03 & 3 & 0.45 & 1.62 & 24. & 5 & 800 & 0.03 & 3 & 0.46 & 1.99 \\
\hline 7. & 8 & 300 & 0.1 & 3 & 3 & 2.45 & 25. & 8 & 300 & 0.1 & 3 & 3.06 & 3.34 \\
\hline 8. & 8 & 500 & 0.03 & 5 & 1.01 & 1.96 & 26. & 8 & 500 & 0.03 & 5 & 1.2 & 2.55 \\
\hline 9. & 8 & 800 & 0.05 & 0 & 1.61 & 2.13 & 27. & 8 & 800 & 0.05 & 0 & 1.68 & 2.67 \\
\hline 10. & 3 & 300 & 0.03 & 0 & 0.36 & 0.33 & 28. & 3 & 300 & 0.03 & 0 & 0.5 & 0.46 \\
\hline 11. & 3 & 500 & 0.05 & 3 & 0.25 & 0.77 & 29. & 3 & 500 & 0.05 & 3 & 0.3 & 0.9 \\
\hline 12. & 3 & 800 & 0.1 & 5 & 0.53 & 3.13 & 30. & 3 & 800 & 0.1 & 5 & 0.62 & 3.66 \\
\hline 13. & 5 & 300 & 0.05 & 5 & 0.81 & 0.8 & 31. & 5 & 300 & 0.05 & 5 & 1 & 1.1 \\
\hline 14. & 5 & 500 & 0.1 & 0 & 1.38 & 3.01 & 32. & 5 & 500 & 0.1 & 0 & 1.55 & 3.36 \\
\hline 15. & 5 & 800 & 0.03 & 3 & 0.46 & 1.81 & 33. & 5 & 800 & 0.03 & 3 & 0.48 & 2.32 \\
\hline 16. & 8 & 300 & 0.1 & 3 & 3.03 & 2.9 & 34. & 8 & 300 & 0.1 & 3 & 3.1 & 3.78 \\
\hline 17. & 8 & 500 & 0.03 & 5 & 1.1 & 2.26 & 35. & 8 & 500 & 0.03 & 5 & 1.3 & 2.85 \\
\hline 18. & 8 & 800 & 0.05 & 0 & 1.64 & 2.4 & 36. & 8 & 800 & 0.05 & 0 & 1.71 & 2.91 \\
\hline
\end{tabular}

The simulation of trained ANN was conducted using the value of the torque, acquired for the twist drills wear values $V B=0.04 d$ for all the combinations of input parameters; after training of each network, a simulation was performed and verified that the neural network satisfies the error aspect for each individual result. The data used for simulation are given in Table 12.

Table 12. ANNs simulation data.

\begin{tabular}{ccccccc}
\hline No. & \multicolumn{3}{c}{ Inputs } & \multicolumn{2}{c}{ Output } \\
\cline { 2 - 7 } & $\boldsymbol{d}$ & $\boldsymbol{n}$ & $\boldsymbol{f}$ & $\boldsymbol{\varepsilon}$ & $\boldsymbol{M}$ & $\boldsymbol{R}_{\boldsymbol{a}}$ \\
\hline 1. & 3 & 300 & 0.03 & 0 & 0.58 & 0.57 \\
2. & 3 & 500 & 0.05 & 3 & 0.33 & 0.97 \\
3. & 3 & 800 & 0.1 & 5 & 0.66 & 4.01 \\
4. & 5 & 300 & 0.05 & 5 & 1.12 & 1.31 \\
5. & 5 & 500 & 0.1 & 0 & 1.63 & 3.49 \\
6. & 5 & 800 & 0.03 & 3 & 0.5 & 2.65 \\
7. & 8 & 300 & 0.1 & 3 & 3.13 & 4.22 \\
8. & 8 & 500 & 0.03 & 5 & 1.4 & 3.14 \\
9. & 8 & 800 & 0.05 & 0 & 1.74 & 3.15 \\
\hline
\end{tabular}

Training, simulation, and verification that the network results satisfy an individual error of up to $5 \%$ were first performed with an ANN with five neurons in one hidden layer (network type 5-1). Since the mentioned network did not give the required results in terms of individual error, the number of neurons was increased and simulation and verification of the results of such networks was performed 
(types of networks 10-1 and 15-1). As the aforementioned ANNs did not produce results in terms of individual error, training and simulation of a network with two hidden layers was performed, whereby the number of neurons was increased to obtain satisfactory accuracy (types of networks 10-5-1, 10-10-1, and 15-10-1). The results obtained by simulating ANNs of different architectures with individual errors relative to the experimental results are given in Table 13.

Table 13. Simulation results with calculated error.

\begin{tabular}{|c|c|c|c|c|c|c|c|c|c|c|c|c|c|}
\hline No. & $\begin{array}{c}R a \\
(\mu \mathrm{m})\end{array}$ & \multicolumn{6}{|c|}{$R a(\mu \mathrm{m})-\mathrm{ANN}$ Result } & \multicolumn{6}{|c|}{ ANN Error (\%) } \\
\hline 1. & 0.57 & 0.69 & 0.5 & 0.48 & 0.45 & 0.6 & 0.59 & 21.05 & 12.28 & 15.79 & 21.05 & 5.26 & 3.51 \\
\hline 3. & 4.01 & 3.99 & 3.96 & 3.93 & 3.7 & 3.75 & 4.03 & 0.5 & 1.25 & 2 & 7.73 & 6.48 & 0.5 \\
\hline 4. & 1.31 & 1.47 & 0.94 & 1.02 & 1.3 & 1.39 & 1.37 & 12.21 & 28.24 & 22.14 & 0.76 & 6.11 & 4.58 \\
\hline 5. & 3.49 & 3.4 & 3.51 & 3.5 & 3.49 & 3.37 & 3.42 & 2.58 & 0.57 & 0.29 & 0 & 3.44 & 2.01 \\
\hline 7. & 4.22 & 3.83 & 4.22 & 4.21 & 4.2 & 4.22 & 4.14 & 9.24 & 0 & 0.24 & 0.47 & 0 & 1.9 \\
\hline 8. & 3.14 & 3.7 & 2.97 & 3.13 & 3.15 & 3.11 & 3.11 & 17.83 & 5.41 & 0.32 & 0.32 & 0.96 & 0.96 \\
\hline 9. & 3.15 & 3.13 & 3.25 & 3.16 & 3.12 & 3.16 & 3.11 & 0.63 & 3.17 & 0.32 & 0.95 & 0.32 & 1.27 \\
\hline \multicolumn{8}{|c|}{ Mean error (\%) } & 7.31 & 6.28 & 5.55 & 4.09 & 3.25 & 2.13 \\
\hline
\end{tabular}

Simulation results with a maximum individual error of less than $5 \%$ were obtained by a neural network with 15 neurons in the first hidden layer and 10 neurons in the second hidden layer (network type 15-10-1), as shown in Figure 4, which is taken as a model.

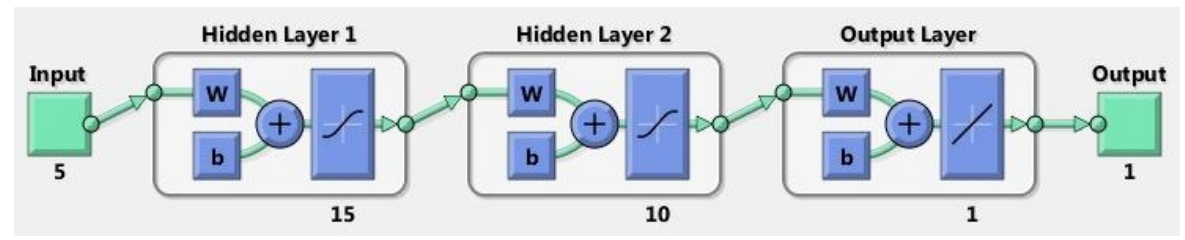

Figure 4. The architecture of the selected ANN.

In addition to achieving the best simulation results, the ANN type 15-10-1 also achieved the best training, testing, and validation results. The results of ANN training are shown in Figure 5.
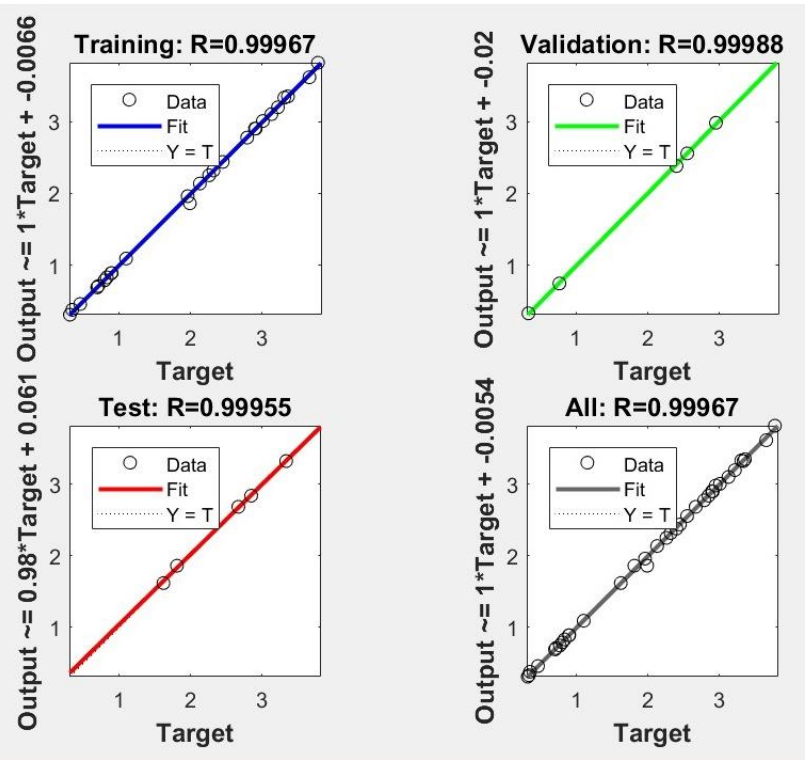

Figure 5. The results of neural network training. 
Weights between inputs and hidden layer (w), hidden layers biases (b1 and b2), and output layer biases (b3) of the developed ANN are shown in Table 14, while weights of hidden layers (w1 and w2) are shown in Table 15.

Table 14. Weights between inputs and hidden layer and biases of developed ANN.

\begin{tabular}{|c|c|c|c|c|c|c|c|c|}
\hline Neuron & & & $\mathbf{w}$ & & & b1 & b2 & b3 \\
\hline 1. & -1.359 & -0.523 & 1.027 & -0.291 & 1.529 & 2.69 & 1.472 & -0.129 \\
\hline 2. & -0.946 & 1.104 & -1.632 & 0.579 & 0.967 & 2.211 & -0.992 & \\
\hline 3. & -1.493 & 1.061 & -0.711 & -0.588 & -1.317 & 1.546 & -0.477 & \\
\hline 4. & 0.745 & 1.475 & -0.343 & 1.703 & 1.147 & -1.384 & 0.464 & \\
\hline 5. & 0.126 & 0.213 & -0.587 & 1.91 & -1.391 & 1.184 & -0.441 & \\
\hline 6. & 0.117 & -1.454 & 0.916 & -1.444 & -2.791 & 0.232 & 0.251 & \\
\hline 7. & 0.852 & -1.313 & 0.806 & 0.002 & 1.641 & -0.153 & -0.467 & \\
\hline 8. & -0.614 & -1.803 & 1.077 & -0.505 & -1.036 & 0.373 & -1.165 & \\
\hline 9. & 1.12 & -1.133 & 1.096 & 0.954 & -0.911 & 0.472 & -1.321 & \\
\hline 10. & 0.856 & -0.173 & 0.678 & -1.547 & -2.08 & 0.484 & -1.65 & \\
\hline 11. & 0.014 & 1.257 & 0.069 & 0.88 & -2.092 & 1.07 & & \\
\hline 12. & 0.106 & -0.435 & 1.708 & -1.657 & 0.54 & 1.393 & & \\
\hline 13. & -0.688 & -0.789 & -1.314 & -1.262 & -1.394 & -1.588 & & \\
\hline 14. & 0.98 & -1.432 & -1.407 & 0.021 & 0.763 & 2.084 & & \\
\hline 15. & 0.0858 & 0.652 & 1.732 & 1.22 & -1.126 & 2.466 & & \\
\hline
\end{tabular}

Table 15. Weights of hidden layers of developed ANN.

\begin{tabular}{ccccccccccccc}
\hline Neuron & \multicolumn{1}{c}{$\mathbf{c}$ w1 } \\
\hline 1. & -0.342 & 0.544 & 1.297 & -0.304 & 0.448 & 0.364 & -0.414 & -0.518 & -0.311 & -0.73 & -0.432 \\
2. & 0.436 & -0.53 & 0.883 & -0.449 & -0.008 & -0.379 & 0.377 & 0.209 & -0.301 & 0.351 & -1.186 \\
3. & -0.941 & -1.084 & 0.783 & 1.075 & -0.289 & 0.625 & 0.109 & 0.249 & 0.404 & 0.212 & 1.403 \\
4. & 0.73 & -0.2 & 0.227 & 0.179 & 1.533 & 0.567 & -0.46 & 0.354 & 0.501 & 0.0447 & 1.153 \\
5. & 0.512 & 0.349 & -0.94 & 0.029 & 0.686 & -0.236 & -0.228 & -0.612 & 0.318 & 0.108 & 1.571 \\
6. & 0.72 & -0.287 & -0.828 & -0.998 & -1.612 & -0.023 & -0.899 & -0.098 & -0.634 & 0.656 & -1.128 \\
7. & -0.505 & 0.585 & -0.372 & -0.192 & 0.109 & -0.036 & 0.309 & 0.791 & -0.374 & 0.007 & 0.561 \\
8. & 0.418 & 0.286 & 0.264 & 0.792 & -1.014 & -0.865 & 0.298 & -0.241 & 0.328 & -0.433 & 0.788 \\
9. & 0.303 & 0.999 & -0.095 & 0.103 & -0.403 & -0.525 & 0.113 & 0.287 & 0.182 & -0.759 & 0.396 \\
10. & -0.137 & 0.184 & -0.262 & -1.337 & -1.115 & 0.151 & -0.866 & -0.25 & -0.003 & -0.516 & -1.302 \\
11. & -0.298 & -0.031 & -0.699 & 0.851 & 0.233 & 0.818 & 0.138 & -0.312 & -0.259 & -0.307 & \\
12. & 0.242 & -0.261 & -0.241 & 0.205 & -0.871 & -0.47 & 0.81 & 0.464 & 0.727 & -0.772 & \\
13. & -0.059 & 0.322 & 0.017 & -0.391 & -0.215 & -0.029 & -0.114 & -0.436 & 0.735 & 0.48 & \\
14. & -0.001 & 0.896 & -0.345 & -0.091 & -0.144 & -0.663 & 0.164 & -0.404 & 0.15 & 0.111 & \\
15. & -0.372 & 0.918 & 0.812 & 0.582 & -0.139 & -0.153 & -0.581 & 0.432 & 0.229 & 0.475 & \\
\hline
\end{tabular}

\section{The Discussion}

The comparative results of the experiment, regression models and ANN model are shown in Table 16.

Based on the comparative analysis of the experimental results and the multiple linear regression model, it can be observed that an error of the model ranges from $1.18 \%$ to $63.16 \%$, while a mean error of the multiple linear regression model with torque is $22.99 \%$.

According to the comparative analysis of the experimental results and the multiple nonlinear regression model, it can be observed that an error in the model ranges from $3.51 \%$ to $28.57 \%$, while a mean error of the multiple nonlinear regression model with torque is $13.03 \%$.

If the experimental results are compared with the results of the model based on ANN s, it can be noticed that the error in the model is in range from $0.5 \%$ to $4.58 \%$, while a mean error of the model based on ANN s with torque is $2.13 \%$. 
Table 16. The comparative analysis of experimental results and models with torque for TD drilling with $\mathrm{CB}$ in test tubes hardness $28 \mathrm{HRC}$.

\begin{tabular}{|c|c|c|c|c|c|c|c|}
\hline \multirow{2}{*}{ No. } & \multirow{2}{*}{$R_{a}(\mu \mathrm{m})$} & \multicolumn{3}{|c|}{$R_{a}(\mu \mathrm{m})-$ Model Results } & \multicolumn{3}{|c|}{ Model Error (\%) } \\
\hline & & MLRM & MNRM & ANNM & MLRM & MNRM & ANNM \\
\hline 1. & 0.57 & 0.21 & 0.55 & 0.59 & 63.16 & 3.51 & 3.51 \\
\hline 2. & 0.97 & 1.48 & 1.05 & 0.98 & 52.58 & 8.25 & 1.03 \\
\hline 3. & 4.01 & 3.85 & 4.24 & 4.03 & 3.99 & 5.74 & 0.5 \\
\hline 4. & 1.31 & 1.82 & 1.58 & 1.37 & 38.93 & 20.61 & 4.58 \\
\hline 5. & 3.49 & 3.27 & 2.8 & 3.42 & 6.3 & 19.77 & 2.01 \\
\hline 6. & 2.65 & 2.37 & 2.18 & 2.74 & 10.57 & 17.74 & 3.4 \\
\hline 7. & 4.22 & 4.17 & 3.99 & 4.14 & 1.18 & 5.45 & 1.9 \\
\hline 8. & 3.14 & 2.69 & 2.9 & 3.11 & 14.33 & 7.64 & 0.96 \\
\hline 9. & 3.15 & 3.65 & 4.05 & 3.11 & 15.87 & 28.57 & 1.27 \\
\hline \multicolumn{5}{|c|}{ Mean error of the model (\%) } & 22.99 & 13.03 & 2.13 \\
\hline
\end{tabular}

A graphical comparative representation of the experimental results (EXP) and the results of the developed models is shown in Figure 6.

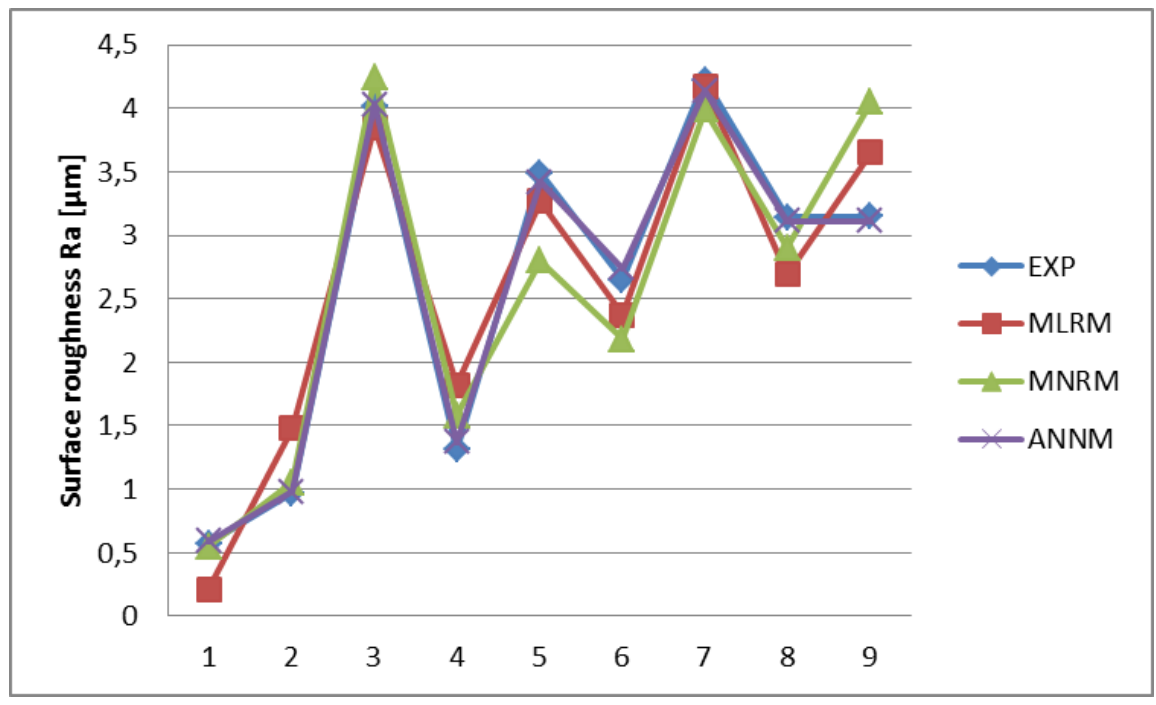

Figure 6. Graphical representation of experiment and models results.

\section{Conclusions}

The subject research showed that it is possible to develop models establishing a connection between input parameters of the drilling process (nominal twist drill diameter, speed, feed, angle of installation of the work piece) and a torque, as a measurable parameter and a provider of information about a tool wear during the process, with the surface roughness by using an arithmetic mean deviation of the roughness profile.

By comparing experimental results of an arithmetic mean deviation of a surface roughness at the moment of tool wear with the results of the multiple regression model and the ANN model, it was concluded that the ANN model provided the best results.

With regard to the results presented in this paper, first of all, the results of the model based on ANN s including torque as a parameter connected to processing tools wear, this research contributes to the possibility of the surface roughness prediction, taking into account the impact of the size of tool wear on the size of a mean arithmetic deviation of a surface's roughness, through torque as a measurable parameter, which was not the case in the previous practice. 
Author Contributions: Conceptualization, Z.K. and R.V.; methodology, Z.K. and D.K.; software, R.V.; validation, Z.K., R.V. and D.K.; formal analysis, R.V. and J.Š.J.; investigation, R.V.; resources, R.V.; data curation, Z.K. and R.V.; writing-original draft preparation, R.V. and J.Š.J.; writing—review and editing, D.K. and J.Š.J.; visualization, J.Š.J. and D.K.; supervision, D.K., Z.K. and J.Š.J. All authors have read and agreed to the published version of the manuscript.

Funding: This research received no external funding.

Conflicts of Interest: The authors declare no conflict of interest.

\section{References}

1. Rodrigues, L.L.R.; Kantharaj, A.N.; Kantharaj, B.; Freitas, W.R.C.; Murthy, B.R.N. Effect of cutting parameters on surface roughness and cutting force in turning mild steel. Res. J. Recent Sci. 2012, 1, 19-26.

2. Çiçek, A.; Kivak, T.; Samtaş, G. Application of Taguchi method for surface roughness and roundness error in drilling of AISI 316 stainless steel. Stroj. Vestn.-J. Mech. Eng. 2012, 58, 165-174.

3. Kumar, P.J.; Packiaraj, P. Effect of drilling parameters on surface roughness, tool wear, material removal rate and hole diameter error in drilling of OHNS. Int. J. Adv. Eng. Res. Stud. 2012, 1, 150-154.

4. Ficici, F.; Koksal, S.; Karacadag, M.C. Optimization of cutting parameters for surface roughness of stainless steel in drilling process. Int. J. Sci. Adv. Technol. 2012, 2, 114-121.

5. Kumari, S.; Goyal, K.K.; Jain, V. Optimization of cutting parameters for surface roughness of stainless steel SS304 in abrasive assisted drilling. Int. J. Mech. Eng. Robot. Res. 2013, 2, 209-215.

6. Xiao, M.; Shen, X.; Ma, Y.; Yang, F.; Gao, N.; Wei, W.; Wu, D. Prediction of surface roughness and optimization of cutting parameters of stainless steel turning based on RSM. Math. Probl. Eng. 2018, 7, 9051084. [CrossRef]

7. Brezocnik, M.; Kovacic, M.; Ficko, M. Prediction of surface roughness with genetic programming. J. Mater. Process. Technol. 2004, 157-158, 28-36. [CrossRef]

8. Sekulic, M.; Pejic, V.; Brezocnik, M.; Gostimirovic, M.; Hadzistevic, M. Prediction of surface roughness in the ball-end milling process using response surface methodology, genetic algorithms, and grey wolf optimizer algorithm. Adv. Prod. Eng. Manag. 2018, 13, 18-30. [CrossRef]

9. Akkuş, H.; Asilturk, I. Predicting surface roughness of AISI 4140 steel in hard turning process through artificial neural network, fuzzy logic and regression models. Sci. Res. Essays 2011, 6, 2729-2736.

10. Konanki, M.N.; Sadineni, R.R. ANN based surface roughness prediction in turning of AA 6351. Int. J. Eng. Res. Appl. 2013, 3, 1455-1459.

11. Rashid, A.; Lani, A. Surface roughness prediction for CNC milling process using artificial neural network. In Proceedings of the World Congress on Engineering, WCE 2010, London, UK, 30 June-2 July 2010.

12. Tamang, S.K.; Chandrasekaran, M. Modeling and optimization of parameters for minimizing surface roughness and tool wear in turning $\mathrm{Al} / \mathrm{SiCp} \mathrm{MMC}$, using conventional and soft computing techniques. Adv. Prod. Eng. Manag. 2015, 10, 59-72. [CrossRef]

13. Hanief, M.; Wani, M.F. Artificial neural network and regression-based models for prediction of surface roughness during turning of red brass (C23000). J. Mech. Eng. Sci. 2016, 10, 1835-1845. [CrossRef]

14. Nedić, B.; Tadić, B.; Đorđević, Z. Some results of testing the impact of tool wear on cutting forces and machined surface quality. Tribol. Ind. 1991, 4, 107-114. (In Serbian)

15. Krivokapić, Z.; Spaić, O.; Vučurević, R. Models for prediction of machined surface quality. Qual. Excell. 2015, 1-2, 84-86. (In Serbian)

16. Mathew, M.T.; Srinivasa, P.P.; Rocha, L.A. An effective sensor for tool wear monitoring in face milling: Acoustic emission. Sadhana 2008, 33, 227-233. [CrossRef]

17. Lin, W.J.; Lo, S.H.; Young, H.T.; Hung, C.L. Evaluation of deep learning neural networks for surface roughness prediction using vibration signal analysis. Appl. Sci. 2019, 10, 1462. [CrossRef]

18. Bhaskaran, J.; Murugan, M.; Balashanmugam, N.; Chellamalai, M. Monitoring of hard turning using acoustic emission signal. J. Mech. Sci. Technol. 2012, 26, 609-615. [CrossRef]

19. Spaić, O.; Marinović, B. Influence of wearing drills on drilling axial force. In Proceedings of the 1st International Scientific Conference Cometa, East Sarajevo-Jahorina, Bosnia and Herzegovina, 28-30 November 2012; pp. 83-90.

20. Xu, Y.; Hiroyuki, K.; Wei, Z. Back propagation wavelet neural network based prediction of drill wear from thrust force and cutting torque signals. Comput. Inf. Sci. 2009, 2, 75-86. 
21. Vučurević, R.; Krivokapić, Z.; Brđanin, R. Comparative analysis of surface quality prediction models. Int. J. Eng. Technol. 2018, 10, 441-449. [CrossRef]

22. Taguchi, G.; Konishi, S. Orthogonal Arrays and Linear Graphs; American Supplier Institute Inc.: Dearborn, MI, USA, 1987.

23. Cavazzuti, M. Optimization Methods: From Theory to Design; Springer: Berlin/Heidelberg, Germany, 2013.

(C) (1)

(C) 2020 by the authors. Licensee MDPI, Basel, Switzerland. This article is an open access article distributed under the terms and conditions of the Creative Commons Attribution (CC BY) license (http://creativecommons.org/licenses/by/4.0/). 